\title{
STUDIES OF THE CIRCULATION IN PERNICIOUS ANEMIA ${ }^{1,2}$
}

\author{
By HAROLD J. STEWART, NORMAN F. CRANE AND JOHN E. DEITRICK \\ (From the New York Hospital and the Department of Medicine, Comell University Medical \\ College, New York City)
}

(Received for publication December 23, 1936)

One of the most important functions of the blood is to furnish oxygen to the tissues in amounts sufficient for their requirements. The human organism has available several compensatory adjustments to counteract alterations which interfere with the normal supply of oxygen. Of these compensatory mechanisms three of the most important are: (1) variation in the oxygen carrying capacity of the blood, that is to say in the quantity of hemoglobin; (2) variation in the quantity of oxygen removed from the blood as it passes through the capillaries; and (3) alteration in the minute-volume output of the heart. It was with the object of studying certain responses of the heart to a slowly developing decrease in the oxygen capacity of the blood, such as is found in patients suffering from pernicious anemia, that these observations were made. We have made, therefore, measurements of the cardiac output, the cardiac size, the venous pressure, the circulation time, the oxygen consumption, the vital capacity, the heart rate, and the blood pressure in five patients suffering from pernicious anemia. These measurements were made first during the anemic state and later during a remission induced by liver extract, when the count of the red blood cells and the hemoglobin values had reached more nearly normal levels. Although there are studies in the literature dealing with certain phases of the circulation, there are none in which the several functions mentioned above were observed simultaneously.

\section{METHODS}

All observations were made in the morning while the patients were in a basal metabolic state. Measurements of the cardiac output were made by the acetylene method,

1 An abstract of these studies was read before the Association of American Physicians, Atlantic City, May 5, 1936.

2 This Paper is also Number 1 of the Series on Studies of the Circulation published from the New York Hospital and the Department of Medicine, Cornell University Medical College. three samples of gas being taken as first recommended by Grollman (1), and by Grollman, Friedman, Clark and Harrison (2). During this measurement the patients were sitting in a steamer chair (angle 135 degrees) with the legs extended. They were trained beforehand to carry out the procedures. While the patient was at rest, the radial pulse was counted at intervals of five minutes. At the end of one-half hour the acetylene-airoxygen mixture was rebreathed. Three samples of gas were taken during each rebreathing period for estimation of the arteriovenous oxygen difference. Three periods of rebreathing were carried out on each patient. Shortly afterward, the oxygen consumption was measured with a Benedict-Roth spirometer. After a short pause, the vital capacity was measured, and height and weight recorded. Then the patient rested again, now lying down. In succession, sufficient time being allowed between each procedure for the patient to return to a basal metabolic state, an electrocardiogram was taken, the arm to tongue circulation time recorded, the venous pressure estimated, and the blood pressure measured; finally an $\mathbf{x}$-ray photograph of the heart was made at a distance of two meters.

The arm to tongue circulation time was estimated by the use of decholin: 5 cc. of a 20 per cent solution were injected rapidly ( 1 to 2 seconds) through an 18 gauge needle into an antecubital vein while the patient was lying quietly in the supine position. This was repeated in one and one-half minutes after the response to the first test had been elicited. The time was recorded from the beginning of the injection until the patient perceived the bitter taste. The injection time was also recorded, but since the response may come with a minimal amount of the drug, the time which we have used was taken from the start, rather than from the conclusion of the injection.

The venous pressure was measured by the direct method (3), using a large antecubital vein, the arm being placed on a level with the right auricle. The apparatus consisted of an L-tube of glass attached to a three-way stopcock, a syringe, and an 18 gauge needle. The apparatus was filled with a solution of sterile normal saline, a venepuncture performed, and the direct pressure readings recorded. Normal pressures with this apparatus range from 4.0 to $9.0 \mathrm{~cm}$. of saline. The antecubital vein of one arm was reserved for the injection of decholin and of the other arm for the measurement of venous pressure. In subsequent measurements the vein was entered at the site first punctured.

$\mathrm{X}$-ray photographs of the heart were taken with the patient in the standing position, in full inspiration, at 
a distance of two meters. ${ }^{3}$ Measurements of the cardiac area were carried out by the technique of Levy (4) and estimations of volume were made as recommended by Bardeen (5). The volumes recorded in Table I have not been multiplied by the constant which is in Bardeen's formula. This was done in order to make our observations comparable to those of Starr, Collins and Wood (13).

\section{OBSERVATIONS}

Case 1, a white woman 39 years of age, was admitted to the hospital on February 6, 1935. For 6 months before admission she had experienced increasing weakness, dyspnea, palpitation, intermittent diarrhea, and a loss in weight of $25 \mathrm{kgm}$. Pallor and swelling of the ankles toward evening appeared during the last two months. On examination the patient was obese and quite pale. The heart was slightly enlarged (Table I). The rhythm was normal sinus mechanism. A systolic murmur was heard at the apex. Neither cyanosis nor dyspnea were observed. Râles were not heard at the lung bases. The liver and spleen were not palpable. Moderate pitting edema was present below the knees. Free hydrochloric acid was not present in the gastric contents after the administration of histamine. The patient was anemic and a blood smear showed changes typical of pernicious. anemia.

On February 9, 1935, when the count of the red blood cells was $1,070,000$, the various measurements recorded in Table $I$ were made. On a regime of injections of liver extract 4 intramuscularly, $10 \mathrm{cc}$. daily for one week followed by biweekly injections of $10 \mathrm{cc}$. of this extract, together with reduced iron 1.5 grams by mouth, daily, the anemia became less severe, and on March 14, 1935, a second series of measurements was recorded (Table I).

Case 2, a white woman 54 years of age, was admitted to the hospital on March 2, 1935. She had first observed dyspnea and palpitation on exertion 11 years before admission. For two years she had experienced severe epistaxis and was then told for the first time that the blood pressure was elevated. Following a recurrence of epistaxis in December 1934, she suffered from increased fatiguability and increasing dyspnea and palpitation on exertion, although she was still able to climb four flights of stairs. Two weeks before admission she became aware of a yellowish pallor of the skin. On examination the patient was obese. There was a pale icteric tint of the skin. The tongue margin was smooth. A firm nodule was felt in the isthmus of the thyroid, but tremor of the hands was not present. The heart was slightly enlarged (Table I). Regular sinus rhythm was present. A systolic murmur was heard at the apex. The second sound over the aortic area was louder than the second

\footnotetext{
3 The authors are deeply indebted to the X-ray Department of the New York Hospital for their cooperation in this investigation.

4 The extract which was given to all patients was prepared at the New York Hospital unless otherwise specified.
}

pulmonic sound. The blood pressure was labile, varying during her stay in the hospital between 130 and $214 \mathrm{~mm}$. of $\mathrm{Hg}$ systolic, and 80 to $126 \mathrm{~mm}$. of $\mathrm{Hg}$ diastolic. Cyanosis, dyspnea, and edema were not observed. A few moist râles were heard at the lung bases at the time of admission. These disappeared during the first few days in bed. The liver and spleen were not palpable. There was a trace of albumin in the urine and occasional red blood cells were present in the centrifuged sediment. The urea clearance was 63 per cent of normal. The gastric contents did not contain free $\mathrm{HCl}$ after the administration of histamine. A blood smear showed the changes typical of pernicious anemia. The following diagnoses were made: Pernicious anemia, arterial hypertension; normal sinus rhythm; obesity due to excess food; and non-toxic nodular goiter.

On March 8 when the count of the red blood cells was $1,190,000$ the first series of measurements was made ( $\mathrm{Ta}$ ble I). The patient then received injections of liver extract intramuscularly, $10 \mathrm{cc}$., daily for one week followed by injections of $10 \mathrm{cc}$. of the extract every third day, together with $12 \mathrm{cc}$. of a 50 per cent solution of iron and ammonium citrate given by mouth daily. On this regime the count of the red blood cells rose to $3,200,000$ on March 27, 1935, and the second series of measurements was recorded (Table I).

Case 3, a white male 66 years of age, was first admitted to the hospital on August 23, 1929, complaining of anorexia and weakness of ten weeks' duration. On examination, marked pallor was present. The count of the red blood cells was $1,110,000$ and the estimation of the hemoglobin was 22 per cent (14.5 grams hemoglobin equivalent to 100 per cent). The blood smear showed changes typical of pernicious anemia. On a diet containing liver the patient improved and was discharged on September 12, the count of the red blood cells then being 2,180,000 and the estimation of the hemoglobin 41 per cent. Three months following discharge he stopped taking liver and felt well until three weeks prior to his second admission when he experienced weakness, diarrhea, tingling of the fingers and toes. He was readmitted to the hospital on February 15, 1935. The patient was a thin, pale, elderly male, who showed no dyspnea, cyanosis nor edema. The heart was not enlarged (Table I). Regular sinus rhythm was present. No murmurs were heard. Râles were not heard at the lung bases; the liver and spleen were not palpable. Neurological changes were not present. The gastric contents did not contain free hydrochloric acid after the administration of histamine, and a blood smear showed the changes typical of pernicious anemia.

On February 19 the count of the red blood cells was $1,410,000$, and the first series of measurements was made (Table I). On a regime of injections of liver extract intramuscularly, $10 \mathrm{cc}$. daily for one week followed by biweekly injections of $10 \mathrm{cc}$. of this extract, together with 1.5 grams of reduced iron by mouth daily, the count of the red blood cells rose to $3,500,000$ on March 9, 1935, and the second series of measurements was recorded (Table I) 


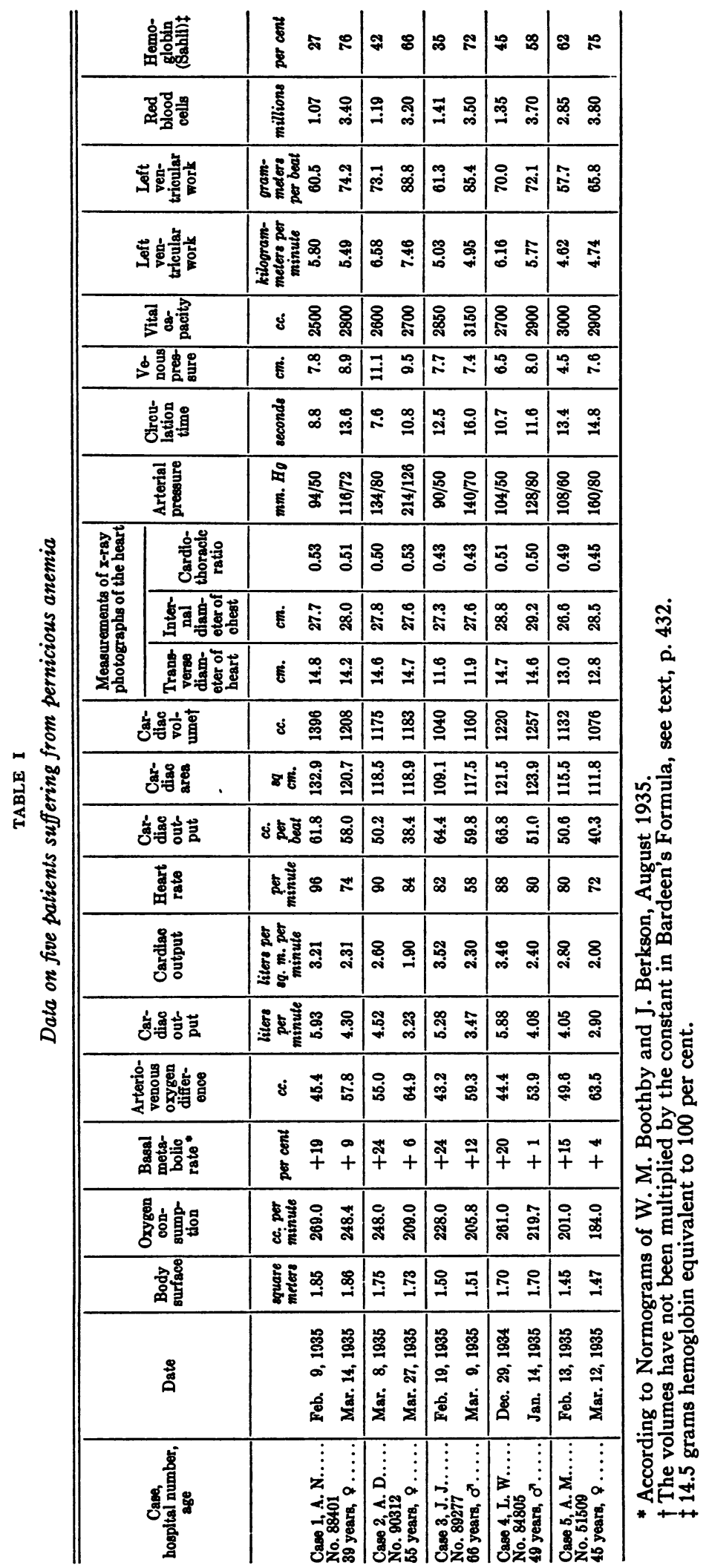


Case 4, a white male 49 years of age, was admitted to the hospital on December 27, 1934. Two years prior to admission he had noticed increasing pallor and had experienced anorexia, soreness of the tongue, weakness, unsteadiness of gait, and numbness and tingling of the feet. For 18 months frequent attacks of vomiting and dyspnea on exertion had been present. For six months, substernal

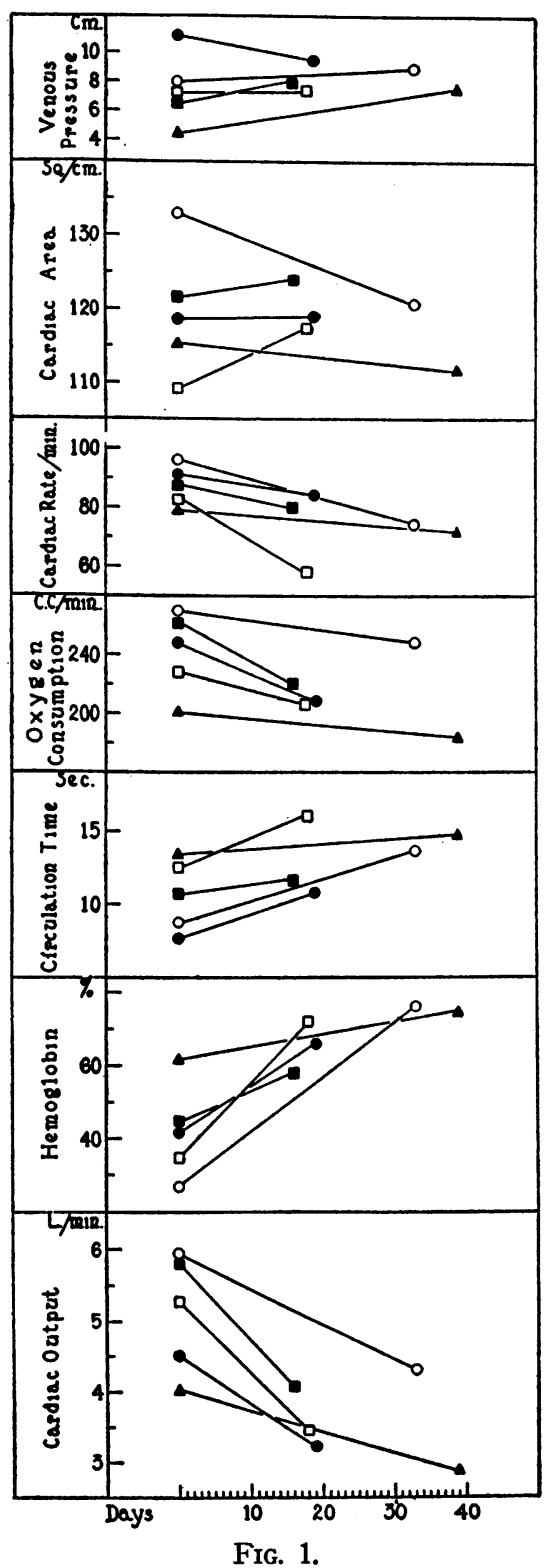

In this figure is represented the effect of low hemoglobin levels in the blood on cardiac output, circulation time, oxygen consumption, cardiac rate, cardiac area, and venous pressure, and the changes which occur with return toward normal hemoglobin, and red blood cell levels. Each symbol represents a patient: Case 1, A. N. = open circle ; Case 2, A. D. = closed circle; Case 3, J. J. = open square; Case 4, L. W. = closed square; Case 5, A. M. $=$ closed triangle. pain, vertigo and fainting were prominent symptoms. During the last two months before applying for admission to the hospital, swelling of the legs and feet became quite marked. There was a yellowish pallor of the skin and slight dyspnea on exertion. The tongue margins were smooth. The heart was slightly enlarged (Table I). Regular sinus rhythm was present, and a systolic murmur was heard at the apex. A few moist râles were heard at the lung bases, and the liver edge was felt two fingers breadths below the costal margin. There was marked edema of the legs and moderate pitting over the sacrum. The patient walked with a spastic gait and both the vibration and position senses of the legs were impaired. The Wassermann reaction in the blood was negative. The gastric contents did not contain free hydrochloric acid after the administration of histamine. A blood smear showed the changes typical of pernicious anemia.

On December 29, 1934, the count of the red blood cells was $1,350,000$ and the previously described series of measurements was made (Table I). On a regime of injections of liver extract intramuscularly, $10 \mathrm{cc}$. daily, for one week, followed by weekly injections of $10 \mathrm{cc}$. of extract, the count of the red blood cells rose to $3,700,000$ on January 14, 1935, and the series of measurements was repeated. The patient showed now only slight dyspnea, there were still occasional râles heard at the lung bases, the liver was no longer palpable, and only slight pitting edema of the ankles remained.

Case 5, a white woman 45 years of age, was admitted to the hospital first on August 27, 1934 . One month before admission she had experienced epigastric distress, numbness and tingling in the hands and feet. On examination the patient showed moderate pallor. The tongue margins were smooth. Dyspnea, cyanosis and edema were not present. The heart was not enlarged (Table I). The liver edge was palpated one finger's breadth below the costal margin. The tendon reflexes, vibration, and position senses were absent in the lower extremities. Free hydrochloric acid was not present in the gastric contents after the administration of histamine. The count of the red blood cells was $2,700,000$, the estimation of the hemoglobin 55 per cent, and a blood smear showed the changes typical of pernicious anemia. Treatment with liver extract was started, the patient receiving liver extract intramuscularly, $10 \mathrm{cc}$. daily for four days followed by weekly injections of $10 \mathrm{cc}$. of the extract. When on September 18, the count of the red blood cells had risen to $3,500,000$ she was discharged from the hospital. In spite of the administration of $12 \mathrm{cc}$. of a 50 per cent solution of iron and ammonium citrate a day, and the weekly injection of $10 \mathrm{cc}$. of New York Hospital intramuscular liver extract, alternating with $9.0 \mathrm{cc}$. of Lederle's intramuscular liver extract, on February 5, 1935, the count of the red blood cells had fallen to $2,300,000$ and she was readmitted to the hospital. The physical signs were essentially the same as on the previous admission.

The patient was immediately given liver therapy intensively. To this end she was given injections daily of New York Hospital intramuscular liver extract, then Lederle intramuscular liver extract and finally ventriculin, 
as well as ferrous sulphate 1.0 gram by mouth three times daily. On February 13, 1935, the count of the red blood cells was $2,850,000$ and the previously described series of measurements was made (Table I).

In summary, it appears from the data of Table I that during the anemic state the cardiac output, the heart rate, and the oxygen consumption were in all cases elevated, and the circulation time short. As the anemia became less the cardiac output, the heart rate, and the oxygen consumption decreased, and the circulation time increased, all approaching more nearly normal values (Figure 1). The venous pressure readings (except in one patient in whom it was initially slightly elevated) and the measurements of the cardiac area showed no significant alterations.

\section{DISCUSSION}

Plesch (6) in 1909, demonstrated that the cardiac output increases when there is decrease in hemoglobin content of the blood. Making use of the Fick principle he found that the increase in cardiac output roughly paralleled the decrease in hemoglobin. Since that time several investigators $(7,8,9,10)$ have measured cardiac output in patients suffering from pernicious anemia. Certain of these employed the same technique that we have used, namely the Grollman method, and others used the nitrous oxide method of Krogh and Lindhard, the Meakins-Davies method, and the Field-Bock method. All reported increase in the cardiac output in anemic patients. There were quantitative variations, however, due probably to experimental errors inherent in all the methods employed (1).

Nielsen (11) using Grollman's acetylene method, made eleven observations of one patient suffering from pernicious anemia. $\mathrm{He}$ found that the augmented values of minute-volume output obtained during the severe anemia gradually fell to normal as the patient improved during a remission. In collecting samples of the gas for analysis, however, he made only two, instead of three collections during each rebreathing period; since, however, his results follow a pattern similar to ours in which 3 samples were collected, it is likely that mixing was attained by his patient. Starr et al. $(12,13)$ using a reliable modification of the ethyl iodide method, made single observations in two cases of pernicious anemia in which the estimation of the hemoglobin was 58 per cent and 45 per cent respectively, and found the cardiac output elevated in one instance, but normal in the other.

Our observations reveal an increase in minutevolume output (Figure 1) and in the cardiac index (liters per square meter per minute) (Figure 2), in all patients at their lowest hemoglobin

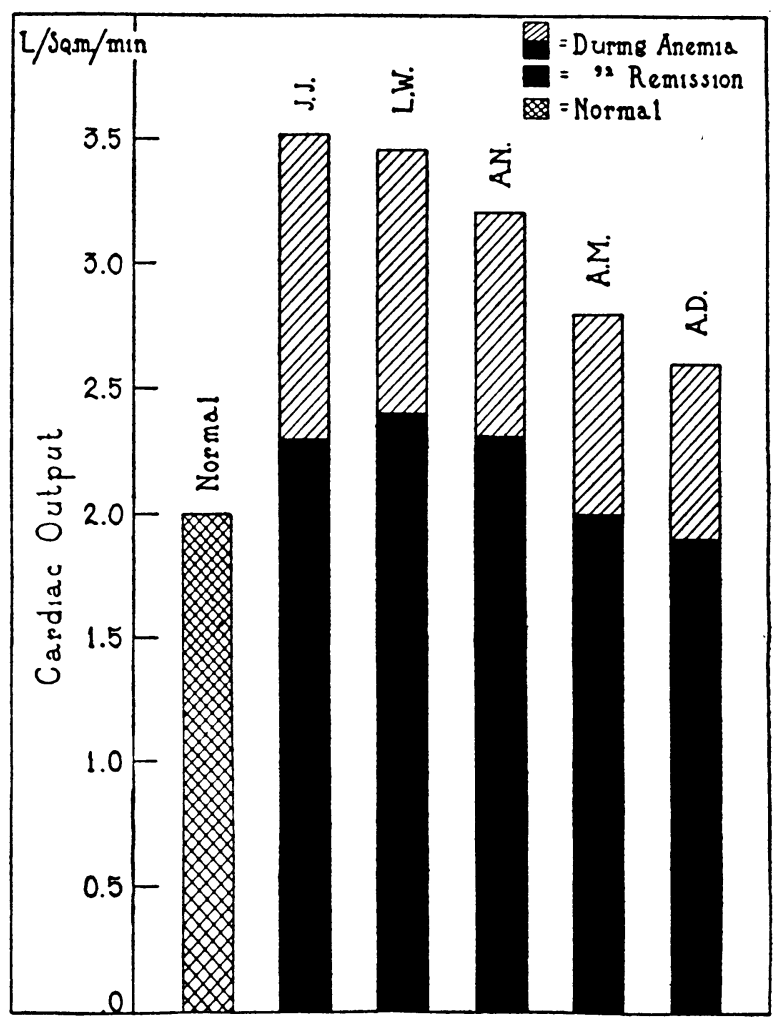

FIG. 2.

In this figure is represented the effect of anemia on the cardiac index (cardiac output in liters per square meter per minute) in each of the five patients studied and the subsequent decrease in cardiac output during a remission induced by intramuscular liver extract therapy. The average value for a normal individual is given for comparison.

values. Increase in cardiac output per minute is due only in part to the rise in oxygen consumption (increase in basal metabolic rate) (Table I), as is shown by the fall in the arteriovenous difference. The direction of our results is similar to that reported by Nielsen (11), although of a smaller magnitude. The arteriovenous oxygen difference (Table I) was in each instance smaller at low hemoglobin levels than after remission occurred. The stroke volume output is also greater during the anemic state even though the 


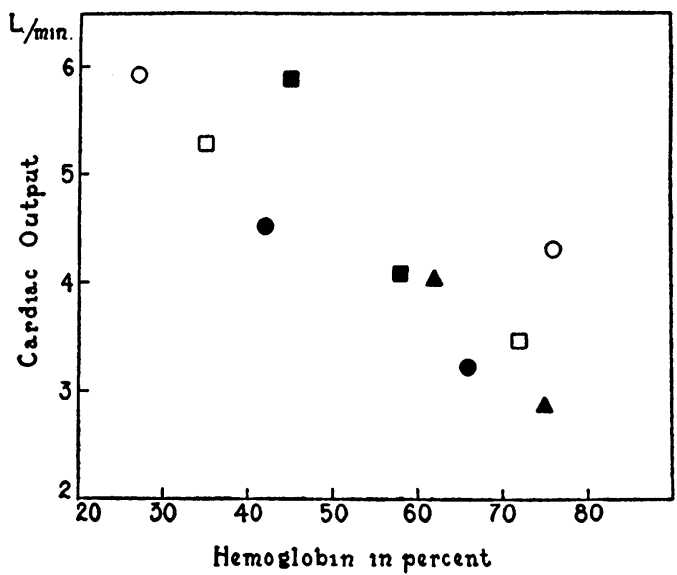

FIG. 3.

In this figure all observations of cardiac output of all patients are plotted against corresponding hemoglobin measurements. This discloses a correlation which appears to be linear, in that as the hemoglobin decreases the cardiac output increases. The symbols representing each patient are the same as those used in Figure 1.

cardiac rates are more rapid than when the red blood cells and hemoglobin have assumed more nearly normal values (Table I) ; the cardiac output decreases progressively as the hemoglobin values (Figure 3 ) and red blood cell counts rise (Figure 4) until normal values of minute-volume output are finally reached at hemoglobin concentration of approximately 70 per cent.

Calculations of the percentage oxygen utilization (Table II) showed that it was greater during

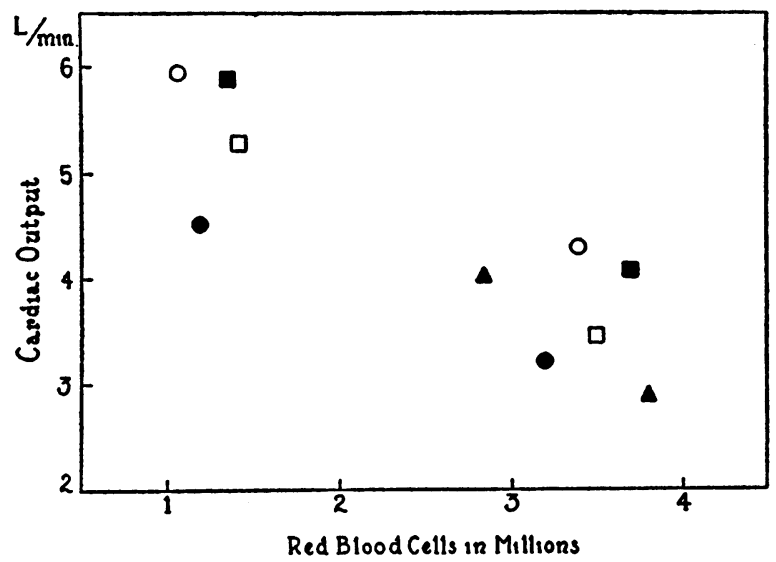

Fig. 4.

In this figure all observations of red blood cell counts of all patients are plotted against the corresponding cardiac output. A correlation similar to that demonstrated in Figure 3 appears. The symbols are the same as those in Figures 1 and 3. the anemic state than after the amount of hemoglobin increased, an observation to which Richards and Strauss (10) have already directed attention as one of the compensatory adjustments in anemia. In short, the percentage oxygen utilization varies inversely as the oxygen capacity (Table II) although the arteriovenous oxygen difference decreases in anemia.

TABLE II

Data relating to percentage of oxygen utilization in 5 anemic patients

\begin{tabular}{|c|c|c|c|c|}
\hline \multirow{2}{*}{$\begin{array}{c}\text { Case } \\
\text { number }\end{array}$} & \multicolumn{2}{|c|}{$\mathrm{O}_{2}$ capacity* } & \multicolumn{2}{|c|}{ Oxygen utilization $\dagger$} \\
\hline & Beforet & After $\ddagger$ & Before & After $¥$ \\
\hline & $\begin{array}{l}\text { volumes } \\
\text { per cent }\end{array}$ & $\begin{array}{l}\text { volumes } \\
\text { per cent }\end{array}$ & per cent & per cent \\
\hline $\begin{array}{l}1 \\
2 \\
3 \\
4 \\
5\end{array}$ & $\begin{array}{r}5.4 \\
8.4 \\
7.0 \\
9.0 \\
12.4\end{array}$ & $\begin{array}{l}15.2 \\
13.2 \\
14.4 \\
11.6 \\
15.0\end{array}$ & $\begin{array}{l}83 \\
65 \\
61 \\
49 \\
40\end{array}$ & $\begin{array}{l}38 \\
49 \\
41 \\
47 \\
43\end{array}$ \\
\hline
\end{tabular}

* 1 per cent hemoglobin (Table I) equivalent to 0.2 volume per cent oxygen capacity. This was assumed to be accurate enough for the deduction to be made from the data derived from the calculations.

$f$ Percentage of oxygen utilization is the ratio between arteriovenous oxygen difference (Table I) and oxygen capacity.

$\ddagger$ "Before" and "After" refer to the period of anemia and period of increased hemoglobin respectively.

In these patients, as the cardiac output increased the velocity of blood flow increased, a

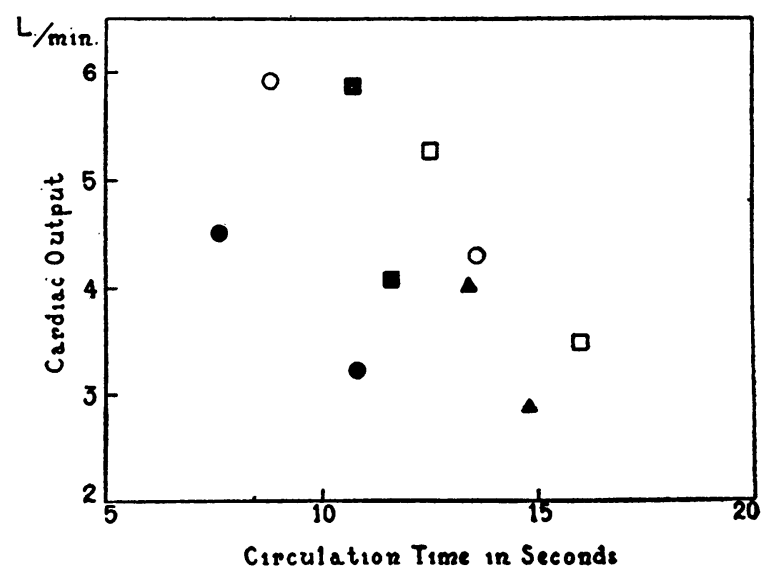

FIG. 5.

In this figure all observations of circulation time are plotted against cardiac output. This reveals a linear correlation in that as the cardiac output decreases the circulation time becomes longer. The symbols are the same as in Figure 1. 


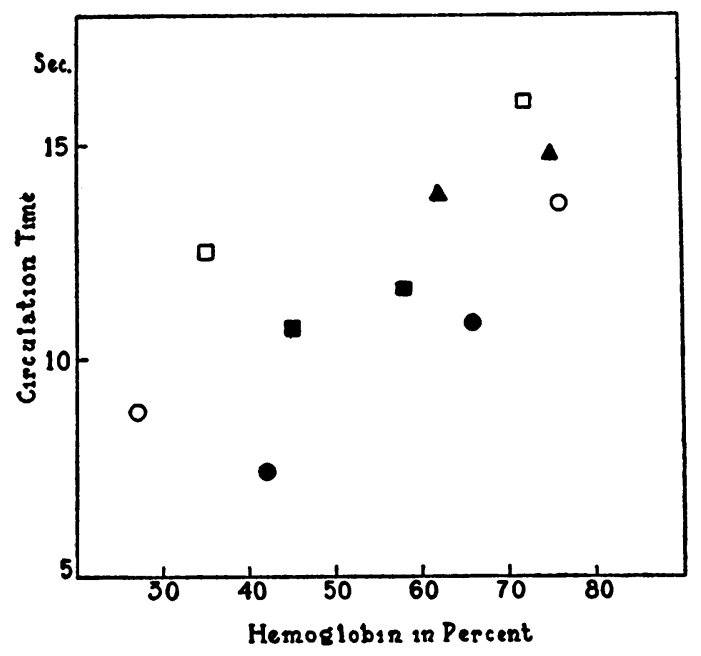

Fig. 6.

In this figure all observations of hemoglobin are plotted against circulation time. A linear correlation appears. As the hemoglobin increases the circulation time becomes longer. The symbols are the same as in Figure 1.

linear relationship being maintained. The greater the cardiac output, the shorter the circulation time (Figure 5). Moreover, there appeared a correlation between circulation time and quantity of hemoglobin; at low hemoglobin percentages the circulation time was short, only to become longer as the hemoglobin values increased (Figure 6).

These results are similar to those recorded in the studies of Blumgart, Gargill and Gilligan (14) relating to velocity of pulmonary blood flow in patients suffering from pernicious anemia. The increase in velocity is, however, of somewhat greater magnitude than that reported by Tarr, Oppenheimer, and Sager (15) who, also using decholin, found an average arm to tongue circulation time of 12 seconds in their anemic patients, as opposed to 13 seconds in their normal control series. Since the hemoglobin levels at which their observations were made are not given it is not possible to make an accurate comparison of their observation with ours.

The venous pressure showed no significant alterations except in the case of one patient (Case 2, Table I) who showed a slightly elevated pressure at the low hemoglobin levels which approached a more normal value as the hemoglobin concentration in the blood increased.

In all patients there was a rise in both the systolic and diastolic levels of blood pressure as the hemoglobin increased; in three instances the increase in blood pressure was very striking. In short, although the heart put out an increased quantity of blood per minute and per beat in the presence of anemia the blood pressure was lower. The manner in which these factors contribute to the work of the heart is discussed later.

The vital capacity of the lungs was moderately reduced in four of the patients during the anemic state although no signs of congestive heart failure were present. We are unable to explain this satisfactorily but call attention to the suggestion offered by Blumgart, Gargill and Gilligan (14) that it may be related to the presence of an increased amount of blood in the lungs coincident with an increased rate of flow.

The electrocardiograms showed no significant alterations as the hemoglobin concentration in the blood increased.

Du Bois (16) has summarized data in the literature relating to the basal metabolic rate in anemia. Certain subjects with anemia show increased and others decreased basal metabolic rates. We have observed increased metabolic rates in each instance at low hemoglobin levels (Table I) ; as the hemoglobin content of the blood increased the oxygen consumption decreased and ap-

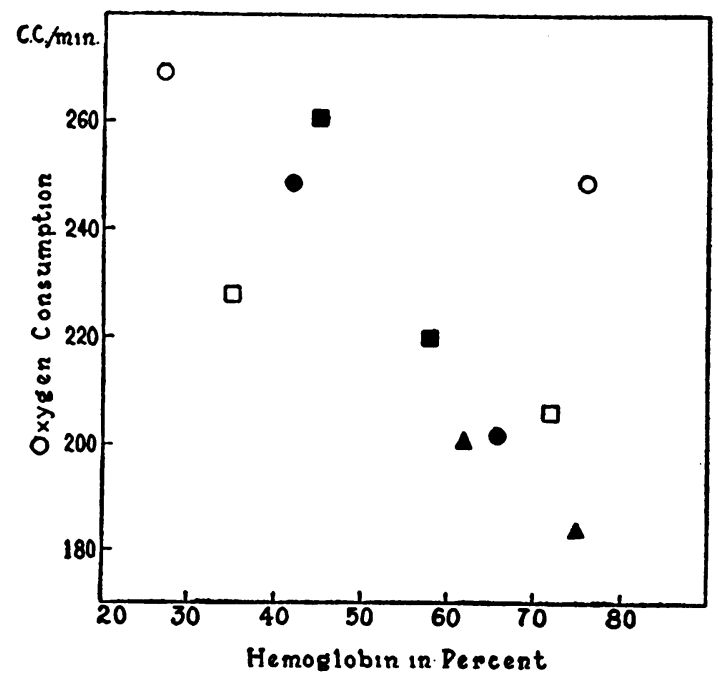

Fig. 7.

In this figure all observations of hemoglobin are plotted against oxygen consumption. A linear relationship is revealed, in that as the hemoglobin increases the oxygen consumption decreases. The symbols are the same as in Figure 1. 
proached more nearly normal values (Figure 7). This result is similar to that growing out of the observations of Tompkins, Brittingham and Drinker (17) who approached this question in another manner. They found that the metabolic rates of patients suffering from pernicious anemia decreased following the transfusion of blood. It appears clear, therefore, both from our own observations and from those already recorded by others, that the oxygen consumption, in short, the basal metabolic rate, may be increased appreciably in the presence of pernicious anemia. A satisfactory explanation for this phenomenon has not yet been advanced. Our data do not permit us to make any positive contribution to this puzzling observation. They indicate, however, as will be shown later, that increased oxygen consumption is not a consequence of increased work of the heart, a notion which has been current up to the present.

That enlargement of the heart in anemic patients occurs as a consequence of both dilatation and hypertrophy is an idea that has been held for many years $(18,19,7)$. Most of the conclusions have been based upon clinical and postmortem observations in cases of pernicious anemia. One patient reported by Ball (20) is of especial interest since roentgenological enlargement of the heart was observed during severe secondary anemia, and was followed by decrease in size when the blood count returned to normal. From these observations he concluded that enlargement was due to dilatation rather than hypertrophy. In the case of three patients in the series now being reported, the heart was moderately enlarged or at the upper limits of normal, only two being well within normal limits. That observations made after improvement failed to show significant change in size of the heart may be due in part to the relatively short time covered by observations of each patient.

The cause of cardiac enlargement found in the presence of anemia has been subject to controversy. One notion (11) regards it as a consequence of increased activity of the heart; another (7) attributes it to lack of oxygen in the myocardium. Because of these notions it appeared of interest to ascertain the amount of work done by the heart in patients suffering from pernicious anemia. Work may be calculated by making use of the formula (21)

$$
W=Q R+\frac{w V^{2}}{2 g}
$$

in which $W$ equals work done per minute, or per beat; $Q$ equals volume of blood expelled per minute, or per beat; $R$ equals mean arterial blood pressure in $\mathrm{mm}$. of $\mathrm{Hg} \times 13.6 ; V$ equals velocity of blood at aorta; $w$ equals weight of blood; $g$ equals acceleration due to gravity. The last part of the formula, $\frac{\left(w V^{2}\right)}{2 g}$, has been omitted in order to make our results comparable to those of Starr et al. (13). By substituting values in this formula, we have calculated the work of the left ventricle both per beat and per minute. Since there is evidence (22) that the work of the right ventricle bears a constant relationship to that of the left, we have concerned ourselves only with the latter. The work per beat done by the left ventricle was found less during the period of increased cardiac output at low hemoglobin levels, than later when the output was lowered and the amount of hemoglobin more nearly normal (Table I).

Taking into account the increased heart rates found in the anemic state, as is done in computing the work per minute, does not reveal increased work in the presence of anemia. This is due for the most part to the considerable increase in the mean arterial pressure which is found at the higher levels of hemoglobin. Since, therefore, the work of the heart appears to be within normal limits there seems to be no point in retaining the notion which is current, that enlargement of the heart in anemia is a consequence of increased cardiac work; on the other hand, by exclusion it lends credence to the view that myocardial anoxemia may be the stimulus which initiates enlargement. Likewise, since we have failed to find the work of the heart increased in these patients, this mechanism does not account for the increased basal metabolic rate.

Stewart and Cohn (23) expressed the opinion that the explanation of the increase in cardiac output with decrease in cardiac size as a consequence of giving digitalis to patients suffering from congestive heart failure, was to be found in Starling's "Law of the Heart" (24). Further- 
more, Starr and his associates $(12,13)$ have presented since then, data indicating that this "Law" applies to basal cardiac work in human beings, as well as to the heart-lung preparation. For it

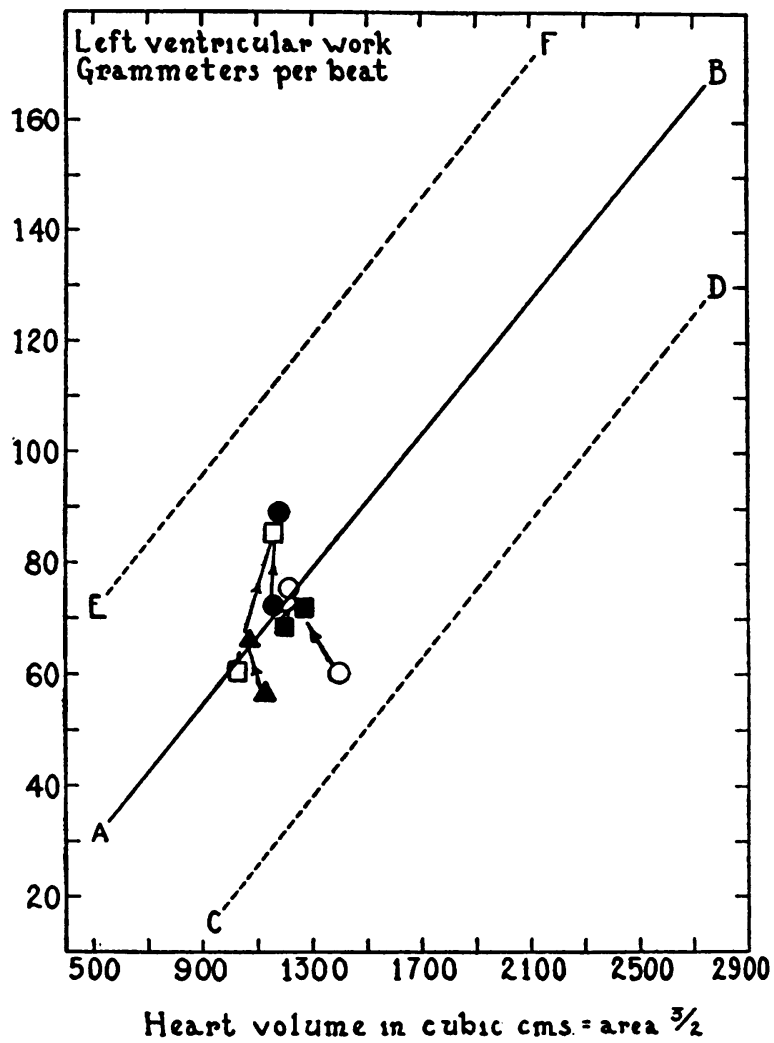

\section{Fig. 8. Left Ventricular Work Per Beat and Cardiac Volume.}

The data from Table I relating to work of the left ventricle per beat are plotted against the corresponding cardiac volumes. Line $A B$ represents the best line, the regression of the work on the area, defined by Starr, Collins and Wood (13, Figure 2) on the basis of a statistical treatment of data from a control group of cases. Lines $C D$ and $E F$ are placed by these authors at a distance of twice the standard deviation from $A B$. It appears from their observatoins that a patient falling within zone $C D-E F$ has a normal circulatory function, that is to say, the work of the heart is commensurate with its size; on the other hand they found that the values relating to patients who had suffered from cardiac decompensation, fell in a zone below $C D$. The values of the patients suffering from pernicious anemia now being reported fall well within the zone $C D-E F$ and, as a matter of fact, lie quite near the best line $A B$. The arrows in each instance point from the first observation during anemia toward the second observation after the hemoglobin had increased. In 4 instances, progression was made toward or even above the best line, and in the fifth remained unchanged. appears to be a fact that the work of the left ventricle which is maintaining an adequate circulation, bears a linear relation to the size of the heart. From a statistical analysis of their data they have defined a zone of normal circulatory function. In a similar fashion we have plotted cardiac volume as abscissae and grammeters of work of the left ventricle per beat as ordinates (Figure 8). All our observations fall within the zone of normal circulatory function, between lines $C D$ and $E F$, very near the best line, $A B$; in each instance, the work of the heart was commensurate with its size. As the degree of anemia lessened, the values for four of the patients moved upward slightly, either toward or above the "best" line $(A B)$, indicating improved cardiac function where the cardiac work is more commensurate with the cardiac size. Thus, in spite of low hemoglobin and red blood cell values during the anemic state, and presumably a decreased total blood volume (23) as well, these patients all exhibit normal cardiac function at rest. This is made possible, apparently, by a distribution of the burden that is placed on the circulatory apparatus as a result of the diminished oxygen capacity of the blood and of the increased metabolic demands of the tissues. A part of this deficit is absorbed by compensatory increase in minutevolume output and in velocity of blood flow, and a part, as has been demonstrated already by Richards and Strauss (10) and now again shown by our data, by increased percentage utilization of oxygen by the tissues. Thus, the adjustments resorted to by the anemic individual call for considerable encroachment on the reserves of the body. In the clinic evidence of this encroachment is revealed in dyspnea and other signs of circulatory failure exhibited by anemic patients when they try to indulge in muscular exertion.

\section{SUMMARY}

1. Measurements of cardiac output, by the acetylene method, of cardiac size, and related circulatory functions, have been made in five cases of pernicious anemia both during the period of anemia, and later during a remission induced by the use of liver extract therapy, when the blood picture was more nearly normal.

2. At low hemoglobin levels in the blood. the 
stroke-volume and minute-volume output, the cardiac rate, and the oxygen consumption were in all cases elevated, and the arm to tongue circulation time decreased. Changes in the reverse direction occurred as the state of the blood approached normal.

3. In four instances the vital capacities were moderately lowered during anemia.

4. The venous pressure and electrocardiograms showed no significant alterations during the anemic state.

5. There was a rise in both the systolic and diastolic levels of blood pressure in all patients as the hemoglobin concentration increased.

6. Although the cardiac size was moderately increased in three instances, no significant change in size was observed as the hemoglobin approached a normal level.

7. Left ventricular work, both per beat and per minute, was not increased during anemia; in fact, the work per beat was less than when the hemoglobin concentration in the blood was normal. It is suggested that the enlarged hearts found in this type of anemia are due to myocardial anoxemia, rather than to increased cardiac work. The elevated metabolic rates, observed in these patients during the anemic state, were not due to increased cardiac work.

8. The amount of cardiac work done at rest, in anemia, was commensurate with the cardiac size.

9. From these observations it appears that during the anemia of pernicious anemia, the heart is called upon to pump an increased amount of blood per minute, the amount appearing to be a linear function of the hemoglobin concentration. This is accomplished in part by increasing the heart rate, and in part, by maintaining a greater output per beat than they have at higher hemoglobin levels. These alterations are reflected in a shortening of the circulation time; in short, the red blood cells, although fewer in number, move at an increased velocity and, as a consequence, they are used more frequently in their oxygen carrying capacity. Shortening of the circulation time and increase in cardiac output as well as decrease in hemoglobin and increase in oxygen consumption also appear to have linear relationships so that an organ already working at an accelerated rate is put to the disadvantage of having to maintain a circulation sufficient for the requirements of an increased basal metabolic rate. With increase in the level of hemoglobin, changes in the reverse direction occur. Nevertheless, the hearts of these patients, without congestive heart failure, at rest, mechanically perform the work expected of them for their size.

\section{BIBLIOGRAPHY}

1. Grollman, A., The Cardiac Output of Man in Health and Disease. C. C. Thomas, Springfield, Ill., 1932, p. 73.

2. Grollman, A., Friedman, B., Clark, G., and Harrison, T. R., Studies in congestive heart failure. XXIII. A critical study of methods for determining the cardiac output in patients with cardiac disease. J. Clin. Invest., 1933, 12, 751.

3. Taylor, F. A., Thomas, A. B., and Schleiter, H. G., A direct method for the estimation of venous pressure. Proc. Soc. Exper. Biol. and Med., 1930, 27, 867.

4. Levy, R. L., The size of the heart in pneumonia. A teleroentgenographic study, with observations on the effect of digitalis therapy. Arch. Int. Med., 1923, 32, 359.

5. Bardeen, C. R., Determination of the size of the heart by means of the x-rays. Am. J. Anat., 1918, 23, 423.

6. Plesch, J., Hämodynamische Studien. Ztschr. f. exper. Path. u. Therap., 1909, 6, 380.

7. Fahr, G., and Ronzone, E., Circulatory compensation for deficient oxygen carrying capacity of the blood in severe anemias. Arch. Int. Med., 1922, 29, 331.

8. Liljestrand, G., and Stenström, N., Clinical studies on the work of the heart during rest. II. The influence of variations in the hemoglobin content on the blood flow. Acta. med. Scandinav., 1926, 63, 130.

9. Dautrebande, L., Le Débit Cardiaque dans l'Anémie. Compt. rend. Soc. de biol., 1925, 93, 1029.

10. Richards, D. W., Jr., and Strauss, M. K., Circulatory adjustment in anemia. J. Clin. Invest., 1928, 5, 161.

11. Nielsen, H. E., The circulation in anemic conditions. Acta. med. Scandinav., 1934, 81, 571.

12. Starr, I., Jr., Donal, J. S., Margolies, A., Shaw, R., Collins, L. H., and Gamble, C. J., Studies of the heart and circulation in disease; estimations of basal cardiac output, metabolism, heart size, and blood pressure in 235 subjects. J. Clin. Invest., 1934, 13, 561.

13. Starr, I., Jr., Collins, L. H., Jr., and Wood, F. C., Studies of the basal work and output of the heart in clinical conditions. J. Clin. Invest., 1933, 12, 13.

14. Blumgart, H. L., Gargill, S. L., and Gilligan, D. R., Studies on the velocity of blood flow. XV. The velocity of the blood flow and other aspects of the circulation in patients with "primary" and sec- 
ondary anemia and in two patients with polycythemia vera. J. Clin. Invest., 1931, 9, 679.

15. Tarr, L., Oppenheimer, B. S., and Sager, R. V., The circulation time in various clinical conditions determined by the use of sodium dehydrocholate. Am. Heart J., 1933, 8, 766.

16. Du Bois, E. F., Basal Metabolism in Health and Disease. Lea and Febiger, Philadelphia, 1936, 3d ed., p. 389.

17. Tompkins, E. H., Brittingham, H. H., and Drinker, C. K., The basal metabolism in anemia, with especial reference to the effect of blood transfusion on the metabolism in pernicious anemia. Arch. Int. Med., 1919, 23, 441.

18. Goldstein, B., and Boas, E. P., Functional diastolic murmurs and cardiac enlargement in severe anemias. Arch. Int. Med., 1927, 39, 226.

19. Lewis, T., and Drury, A. N., Observations relating to arteriovenous aneurysm. I. Circulatory manifestations in clinical cases with particular reference to the arterial phenomena of aortic regurgitation. Heart, 1923, 10, 301.

20. Ball, D., Change in the size of the heart in severe anemia. Am. Heart J., 1931, 6, 517.

21. Starling, E. H., Principles of Human Physiology. Lea and Febiger, Philadelphia, 1933, 6th ed., p. 772.

22. Fühner, H., and Starling, E. H., Experiments on the pulmonary circulation. J. Physiol., 1913, 47, 286.

23. Stewart, H. J., and Cohn, A. E., Studies on the effect of the action of digitalis on the output of blood from the heart. III, Part 2. The effect on the output of hearts in heart failure with congestion, in human beings. J. Clin. Invest., 1932, 11, 933.

24. Starling, E. H., The Linacre Lecture on the Law of the Heart, given at Cambridge, 1915. Longmans, Green and Co., London, 1918.

25. Rowntree, L. G., Brown, G. E., and Roth, G. M., The Volume of the Blood and Plasma in Health and Disease. W. B. Saunders, Philadelphia, 1929, p. 97. 